\title{
Aspectos institucionais do campo científico de estudos sobre mineração no Brasil entre 2015 e 2019
}

Neste trabalho analisamos 688 resumos de teses e dissertações defendidas no Brasil entre 2015 e 2019 sobre temas relacionados à atividade mineradora. 0 objetivo é oferecer um quadro geral deste campo de estudos. O levantamento dos resumos foi realizado no catálogo de teses e dissertações da CAPES por meio de busca pela palavra-chave 'mineração'. Procedemos a leitura dos títulos e dos resumos para selecionar apenas trabalhos relacionados à atividade mineradora. Os dados foram analisados nos Softwares R e Iramuteq. Identificamos as principais áreas de conhecimento, instituições e programas de pós-graduação que realizaram estudos sobre aspectos relacionados à mineração nos períodos destacados. Aplicamos o método de Reinert (1993) para encontrar classes temáticas dentro do campo de estudo. Por meio da Análise Fatorial Confirmatória verificamos a posição das áreas de conhecimento e das instituições em relação às classes temáticas. Os resultados revelaram 6 classes, sendo 5 delas organizadas em torno de áreas de conhecimento e 1 reunindo informações sobre os métodos de pesquisa utilizados nos estudos. 0 estudo ainda destaca as principais instituições e temas associados à cada classe.

Palavras-chave: Mineração; Produção de conhecimento; Iramuteq; CAPES; Aspectos institucionais.

\section{Institutional aspects of the scientific field of studies on mining in Brazil between 2015 and 2019}

\begin{abstract}
In this paper, we analyzed 688 abstracts of theses and dissertations defended in Brazil between 2015 and 2019 on topics related to mining activity. The objective is to offer a general picture of this field of studies. The survey of abstracts was carried out in the CAPES catalog of theses and dissertations by searching for the keyword 'mining'. We proceeded to read the titles and abstracts to select only works related to the mining activity. The data were analyzed using Softwares R and Iramuteq. We identified the main areas of knowledge, institutions and graduate programs that carried out studies on aspects related to mining in the highlighted periods. We applied Reinert's method (1993) to find thematic classes within the field of study. Through Confirmatory Factor Analysis, we verified the position of the areas of knowledge and institutions in relation to the thematic classes. The results revealed 6 classes, 5 of them organized around areas of knowledge and 1 gathering information about the research methods used in the studies. The study also highlights the main institutions and themes associated with each class.
\end{abstract}

Keywords: Mining; Knowledge production; Iramuteq; CAPES; Institutional aspects.

Topic: Ensino Superior, Pesquisa e Extensão Reviewed anonymously in the process of blind peer.
Received: 05/06/2021

Approved: 26/06/2021
Antonio Carlos Andrade Ribeiro (iD)

Universidade Federal de Ouro Preto, Brasil

http://lattes.cnpq.br/0977494541313720

http://orcid.org/0000-0003-2196-4143

antonio.ribeiro@ufop.edu.br

Velcimiro Inácio Maia (it)

Universidade Federal de São João Del-Rei, Brasil

http://lattes.cnpq.br/5274925982950540

http://orcid.org/0000-0003-1283-6529

maiavelcimiro@gmail.com

\section{Gabriela Silva Guimarães (iD}

Universidade Federal de Alfenas, Brasil

http://lattes.cnpq.br/8189194896571347

http://orcid.org/0000-0002-7987-4936

gabrielaguimaraesunf@gmail.com
Brunna Louise Ribeiro Silva

Universidade Federal de Alfenas, Brasil

http://lattes.cnpq.br/9090819422933942

http://orcid.org/0000-0002-4990-7469

brunna.louise@gmail.com
Referencing this:

RIBEIRO, A. C. A.; MAIA, V. I.; GUIMARÃES, G. S.; SILVA, B. L. R. Aspectos institucionais do campo científico de estudos sobre mineração no Brasil entre 2015 e 2019. Revista Ibero Americana de Ciências Ambientais, v.12, n.6, p.691-705, 2021. DOI: http://doi.org/10.6008/CBPC2179-6858.2021.006.0057 


\section{INTRODUÇÃO}

A definição de uma agenda de pesquisa é um trabalho árduo que muitas vezes se inicia na graduação quando os estudantes são solicitados a definir um problema de pesquisa quando muitas vezes nem ao menos definiram o assunto que querem estudar. Acreditamos que a situação de pesquisadores em qualquer nível não seja diferente quando decidem iniciar uma nova agenda, embora o acúmulo de experiências anteriores possa facilitar bastante o trabalho. Metaforicamente concebemos a atividade de pesquisa ao desafio de escolher e montar grandes e complexos quebra-cabeças. Este texto configura-se como um exercício de organização do grande quebra-cabeça da pesquisa sobre aspectos relacionados à mineração. Trata-se de um esforço para identificar e situar temas de pesquisa em relação às áreas de conhecimento, às instituições de ensino e pesquisa e aos programas de pós-graduação brasileiros. A metáfora do quebra-cabeça pode ser descrita da forma como se segue.

Um grupo de pessoas é reunido para resolver quebra-cabeças. Em função do tamanho e da complexidade das imagens, a solução de cada uma não pode ser encontrada individualmente. Deste modo, são formadas espontaneamente equipes para realizar o desafio, cuja composição resulta de interesses individuais associados ao assunto do quebra-cabeça. As pessoas que se sentem atraídas pelo assunto florestas, por exemplo, escolhem trabalhar na solução do quebra-cabeça com imagem de florestas. Aquelas que preferem outro assunto (oceano ou ficção científica ou animais etc.) escolhem os desafios com as respectivas imagens.

Dentro das equipes o assunto precisa ser dividido em vários temas que correspondam a setores do quebra-cabeça e fiquem sob a responsabilidade de grupos de trabalhos (GTs) formados por membros da equipe. Os GTs também são formados considerando os interesses individuais. Por exemplo, aqueles interessados em florestas tropicais trabalham na solução deste tema do quebra-cabeça, enquanto os afins de florestas boreais e os afins de florestas temperadas resolvem os respectivos temas e assim sucessivamente.

Por fim, dentro dos GTs cada membro é convidado a escolher uma peça do quebra-cabeça e trabalhar na solução de um único problema por vez. Feita a escolha, cada participante passa a ter sob sua responsabilidade uma peça-problema do quebra-cabeça e uma questão a responder: como minha peça deve ser encaixada no quebra-cabeça? Seu desafio envolverá: buscar a colaboração de quem já trabalhou com aquele tema do quebra-cabeça; investigar quais são as peças-problema adjacentes; pesquisar sobre os encaixes já realizados; realizar tentativas de encaixe. Uma vez concluída sua tarefa o participante poderá se dedicar a uma nova peça-problema e o seu trabalho ajudará os demais membros da equipe a solucionar as demais peças-problema.

Assuntos, temas e problemas compõem os níveis do trabalho de pesquisa. Na condição de pesquisadores somos membros de uma comunidade científica dividida em equipes e GTs trabalhando coletivamente na solução de quebra-cabeças. Dedicamo-nos a problemas específicos e quando encontramos a solução estamos prontos para enfrentar um novo desafio. Assim como a solução de um quebra-cabeça é 
mais facilmente encontrada quando sabemos qual é a imagem que está sendo montada, o trabalho de pesquisa é melhor desenvolvido quando partimos de uma visão geral do campo de estudos. Seja para o pesquisador em formação, que ainda encontra muita dificuldade para delimitar sua peça-problema no quebra-cabeça, ou para o pesquisador experiente, que possui várias pistas sobre peças e encaixes do quebracabeça, o trabalho de pesquisa exige colaboração, comunicação, debate e diálogo. Quais são os temas do quebra-cabeça? Como eles se relacionam? Quais pessoas e/ou organizações são responsáveis por eles? Quais peças-problema estão nas fronteiras que delimitam os temas? Estas são questões a serem respondidas no processo de elaboração e execução de uma agenda de pesquisa.

Neste artigo buscamos oferecer uma visão geral do quebra-cabeça dos estudos relacionados à atividade da mineração. Realizamos a análise quantitativa de textos de 688 resumos e palavras-chave de teses e dissertações defendidas entre 2015 e 2019. As questões que orientaram nossa análise são: qual a produção relativa de conhecimento sobre o assunto por ano? Qual a contribuição relativa das áreas de conhecimento na produção de estudos? Quais instituições mais se destacam no campo? Qual é a importância das instituições públicas e privadas nos estudos de aspectos relacionados à mineração? Existe tendenciosidade de gênero na autoria dos estudos e/ou na orientação dos estudos? A tendenciosidade de gênero entre autores/autoras e/ou entre orientadores/orientadoras se manifesta dentro das áreas de conhecimento? Como se localizam áreas de conhecimentos e instituições em relação ao conteúdo qualitativo dos estudos sobre mineração?

Nosso objetivo ao responder essas questões foi oferecer um quadro geral do campo de estudos, em nível de pós-graduação, sobre a atividade mineradora no Brasil entre 2015 e 2019. Especialmente, delimitamos 3 objetivos específicos para orientar nossas análises: (1) Traçar o perfil das teses e das dissertações sobre temas relacionados à atividade mineradora em instituições brasileiras; (2) Identificar campos temáticos de estudos sobre aspectos da atividade mineradora; (3) Investigar a posição relativa ocupada por áreas de conhecimento e por instituições de ensino e pesquisa no campo de estudos sobre a mineração. O estudo se justifica à medida que contribui para desvendar como se produz conhecimento sobre uma atividade econômica que gera tanta riqueza, mas que apresenta altos riscos para o meio ambiente e sociais dos territórios que a recebem.

\section{METODOLOGIA}

Os resumos analisados neste artigo foram selecionados no catálogo de teses e dissertações da CAPES $^{1}$. Inicialmente utilizamos a palavra-chave 'mineração' para identificar os trabalhos. Os resultados foram filtrados para dissertações e teses defendidas nos últimos 5 anos (2019-2015). Tendo em vista que a mineração é um processo de extração de recursos minerais da natureza, podendo ser metálicos (como o ferro, o ouro, o manganês) e não-metálicos (como a argila, o carvão, a areia), a seleção dos resumos incidiu sobre trabalhos que se propunham analisar aspectos relacionados à atividade minerária no Brasil. Por tanto,

\footnotetext{
${ }^{1}$ http://catalogodeteses.capes.gov.br/catalogo-teses/
} 
refinamos nossa seleção a partir da leitura dos títulos, resumos e palavras-chave disponibilizados no catálogo CAPES. O enfoque da seleção abrange múltiplos olhares acerca da discussão sobre a mineração, o que permitiu alcançar estudos em distintas áreas do conhecimento. Foram excluídos trabalhos cujo termo 'mineração' estava associado à mineração de dados ou mineração de informação, sentido que se afasta do objetivo pretendido aqui.

As informações sobre os trabalhos selecionados foram organizadas em dois bancos de dados. Um com variáveis sobre o perfil dos trabalhos, tais como tipo do trabalho, instituições, sexo do autor, sexo do orientador e áreas de conhecimento. Os dados foram analisados quantitativamente no software R. Os resumos e palavras-chave compuseram o segundo banco de dado. Procedemos a análise quantitativa dos textos com o apoio do Software Iramuteq, no qual foi desenvolvida a análise de frequência de palavras (ZIPF, 1949), a classificação hierárquica decrescente (REINERT, 1993) e análise fatorial confirmatória (DUVAL, 2015).

\section{RESULTADOS}

\section{Estatísticas descritivas dos estudos relacionados à mineração}

Entre os 688 trabalhos produzidos no Brasil analisados neste artigo, 23,96\% são trabalhos de doutorado e $76,31 \%$ de mestrado (Gráfico 1).

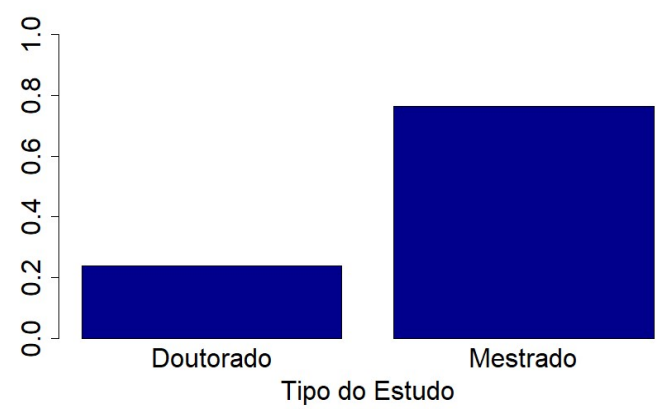

Gráfico 1: Distribuição dos estudos sobre mineração por tipo do trabalho.

Nota-se uma tendência de aumento no interesse pelo assunto da mineração, interrompida em 2019 (Gráfico 2). 0 ano de 2018 aparece como o momento que mais se pesquisou, no nível de pós-graduação, o assunto no Brasil (32,28\%). Neste ano dobrou-se o interesse sobre o assunto em relação ao início do período estudado, o ano de 2015 (15,41\%).

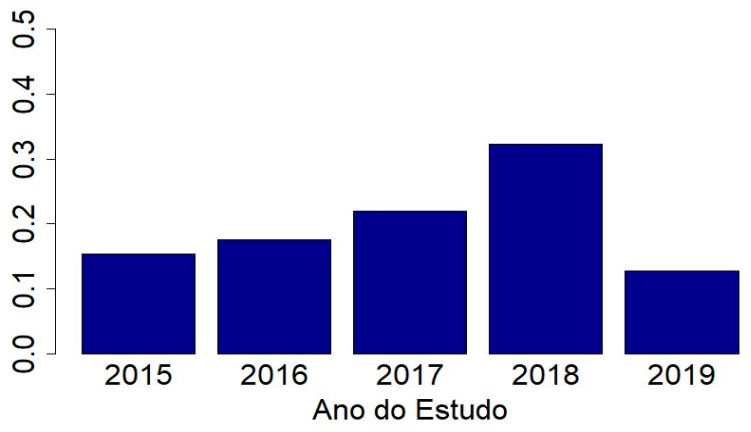

Gráfico 2: Distribuição dos estudos sobre mineração por ano. 
A distribuição dos trabalhos por área de conhecimento mostra que os programas de pós-graduação que mais produziram estudos de mineração nos últimos 5 anos estão ligados à área de Engenharias com 28,34\% dos estudos (Tabela 1). A segunda área a se destacar na produção de conhecimento sobre aspectos relacionados à atividade mineradora é a área de Ciências Sociais Aplicadas (18,34\%). A área de Ciências Humanas ocupou o terceiro lugar com 14,83\% dos estudos. Ciências Ambientais e Ciências Agrárias contribuíram, respectivamente, com 12,21\% e 10,03\% dos trabalhos produzidos. Enquanto que abaixo de 10\% estão as áreas de Ciências Exatas e da Terra (7,12\%), Ciências Biológicas (6,39\%), Ciências da Saúde (2,33\%) e as áreas de Artes e Gestão Contemporânea das Organizações com 1,45\% cada uma.

Tabela 1: Áreas de conhecimento e quantidade relativa de trabalhos produzidos.

\begin{tabular}{ll}
\hline Área & Quantidade relativa de trabalhos \\
\hline Engenharias & $28,34 \%$ \\
Ciências Sociais Aplicadas & $18,46 \%$ \\
Ciências Humanas & $14,83 \%$ \\
Ciências Ambientais & $12,21 \%$ \\
Ciências Agrárias & $10,03 \%$ \\
Ciências Exatas e da Terra & $7,12 \%$ \\
Ciências Biológicas & $6,39 \%$ \\
Ciências da Saúde & $2,33 \%$ \\
Artes & $1,45 \%$ \\
Gestão Contemporânea das Organizações & $1,45 \%$ \\
\hline
\end{tabular}

As contribuições das instituições brasileiras de ensino e pesquisa para produção de conhecimento sobre aspectos relacionados à mineração oscilou entre 1 e 66 estudos produzidos. A tabela 2 mostra as instituições que contribuíram com pelo menos 2 estudos por ano sobre assunto e o peso relativo das mesmas instituições considerando o total de 688 trabalhos defendidos no período analisado. A Universidade Federal de Minas Gerais (UFMG) produziu 9,59\% do total dos estudos. A segunda instituição que mais contribuiu para a produção de conhecimento sobre a mineração foi a Universidade Federal de Ouro Preto (UFOP) com 7,99\% dos estudos, seguida pela Universidade de São Paulo (USP) responsável por 7,27\% da produção. Juntas, as 3 universidades foram responsáveis por quase $1 / 4(24,85 \%)$ dos estudos realizados no período analisado. Compõem o ranking das 5 primeiras as Universidades Federais do Rio Grande do Sul (UFRGS) e do Pará (UFPA), com 5,52\% e 4,07\%, respectivamente.

Os dados registram ainda que das 18 instituições que produziram no mínimo 10 estudos no período, apenas 2 são instituições privadas². Entre as 16 universidades públicas, 13 são Universidades Federais. As 12 instituições que mais produziram conhecimento relacionado à mineração são públicas e foram responsáveis por mais da metade do total de estudos $(52,32 \%)$.

Tabela 2: Áreas de conhecimento e quantidade relativa de trabalhos produzidos.

\begin{tabular}{llll}
\hline Instituição & Tipo & No de estudos & \% de estudos \\
\hline Universidade Federal de Minas Gerais & Pública & 66 & 9,59 \\
Universidade Federal de Ouro Preto & Pública & 55 & 7,99 \\
Universidade de São Paulo & Pública & 50 & 7,27 \\
Universidade Federal de Rio Grande do Sul & Pública & 38 & 5,52 \\
Universidade Federal do Pará & Pública & 28 & 4,07 \\
Universidade Federal de Viçosa & Pública & 24 & 3,49 \\
Universidade Federal do Rio de Janeiro & Pública & 22 & 3,20
\end{tabular}

${ }^{2}$ No universo de 688 estudos, 85,29\% foram realizados em instituições públicas. 
Universidade Estadual Paulista Universidade Federal de Lavras Universidade Federal de Santa Catarina Universidade de Brasília Universidade Federal do Espírito Santo Escola Superior Dom Helder Câmara Universidade Federal do Ceará Universidade Federal de Goiás Universidade Federal de Pernambuco Universidade Federal de Alfenas Universidade Fumec

$\begin{array}{lll}\text { Pública } & 22 & 3,20 \\ \text { Pública } & 21 & 3,05 \\ \text { Pública } & 17 & 2,47 \\ \text { Pública } & 17 & 2,47 \\ \text { Pública } & 14 & 2,03 \\ \text { Privada } & 13 & 1,89 \\ \text { Pública } & 12 & 1,74 \\ \text { Pública } & 11 & 1,60 \\ \text { Pública } & 11 & 1,60 \\ \text { Pública } & 11 & 1,60 \\ \text { Privada } & 10 & 1,45\end{array}$

A fim de caracterizar o perfil dos trabalhos analisados, examinamos a relação entre sexo e autoria, por um lado, e sexo e orientação dos trabalhos, por outro. A figura 1 mostra que a tendenciosidade de gênero manifestou apenas na dimensão de orientação dos trabalhos (66,86\% de trabalhos tiveram orientadores), sendo que a autoria apresentou paridade entre os sexos ( $50,36 \%$ de autoras, $49,63 \%$ de autores).
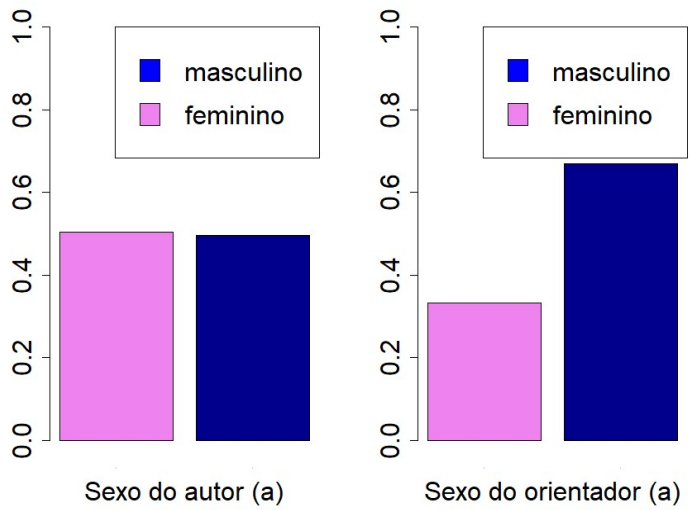

Figura 1: Distribuição de sexo autores e orientadores.

A tabela 3 mostra a distribuição de sexo dos autores e dos orientadores dos trabalhos dentro de cada área. Destaca-se que a maior parte dos trabalhos foram produzidos sob a orientação e escritos por homens da área de Engenharias. A maior atuação de orientadoras ocorreu na área de Ciências Humanas (6,39\% dos trabalhos orientados), embora não tenham superado a atuação dos orientadores nesta área $(8,43 \%)$. Na condição de autoras, as mulheres são minoria na área de Engenharias, Ciências Agrárias e Ciências Humanas. Elas manifestaram uma presença maior em relação aos homens nas demais áreas, principalmente nas áreas de Ciências Biológicas, Ciências Ambientais, Ciências Exatas e da Terra e Ciências Sociais Aplicadas, sendo que nesta última foi a segunda maior área de contribuição das autoras.

Tabela 3: Distribuição de sexo dos autores e dos orientadores por área de conhecimento.

\begin{tabular}{lllll}
\hline Área & \% Autoras & \% Autores & \% Orientadoras & \% Orientadores \\
\hline Engenharias & 11,82 & 16,35 & 5,81 & 22,53 \\
Ciências Sociais Aplicadas & 9,63 & 8,90 & 7,70 & 10,75 \\
Ciências Humanas & 7,30 & 7,60 & 6,39 & 8,43 \\
Ciências Ambientais & 7,00 & 5,25 & 4,51 & 7,70 \\
Ciências Agrárias & 4,38 & 5,55 & 2,03 & 7,99 \\
Ciências Exatas e da Terra & 4,23 & 2,92 & 3,05 & 4,07 \\
Ciências Biológicas & 4,38 & 2,04 & 2,76 & 3,63 \\
Ciências da Saúde & 1,60 & 0,73 & 0,73 & 1,60 \\
Artes & 0,15 & 0,00 & 0,00 & 0,15 \\
Gestão Contemporânea das Organizações & 0,00 & 0,15 & 0,00 & 0,15 \\
\hline
\end{tabular}




\section{Sobre o que falam os estudos: Análise de frequência de palavras}

Segundo a lei de Zipf (1949) o uso recorrente de palavras-chave em um texto revela os principais temas sobre o assunto em debate. Tem-se que ao produzir um texto o autor aplica uma economia de palavras usando de forma recorrente aquelas mais importantes associadas aos temas de interesse. Esta lei fundamenta a análise de frequência de palavras, ao postular que é possível identificar características de um texto ou conjunto de textos por meio do estudo das palavras que mais ocorrem.

Neste estudo analisamos a frequência das palavras nos 688 resumos. O conjunto de resumos foi considerado o corpus textual da pesquisa. A análise de frequência das palavras revelou informações sobre os temas associados ao assunto da mineração analisados nos programas de pós-graduação. No corpus textual foram encontradas 226.896 ocorrências (palavras). Destas 12.897 são formas, isto é, palavras diferentes. Enquanto 5.559 (43,10\% do total de ocorrências) são hápax, ocorrências que apareceram apenas uma palavra.

A figura 2 destaca as ocorrências mais frequentes, sendo o tamanho da palavra a representação de sua importância. Como era de se esperar, a palavra mais utilizada foi 'mineração' que ocorreu 1.623. É recorrente nos estudos a preocupação com os efeitos da mineração (positivos, negativos, ambientais, econômicos, culturais), mas também com os processos e equipamentos relacionadas à atividade econômica.

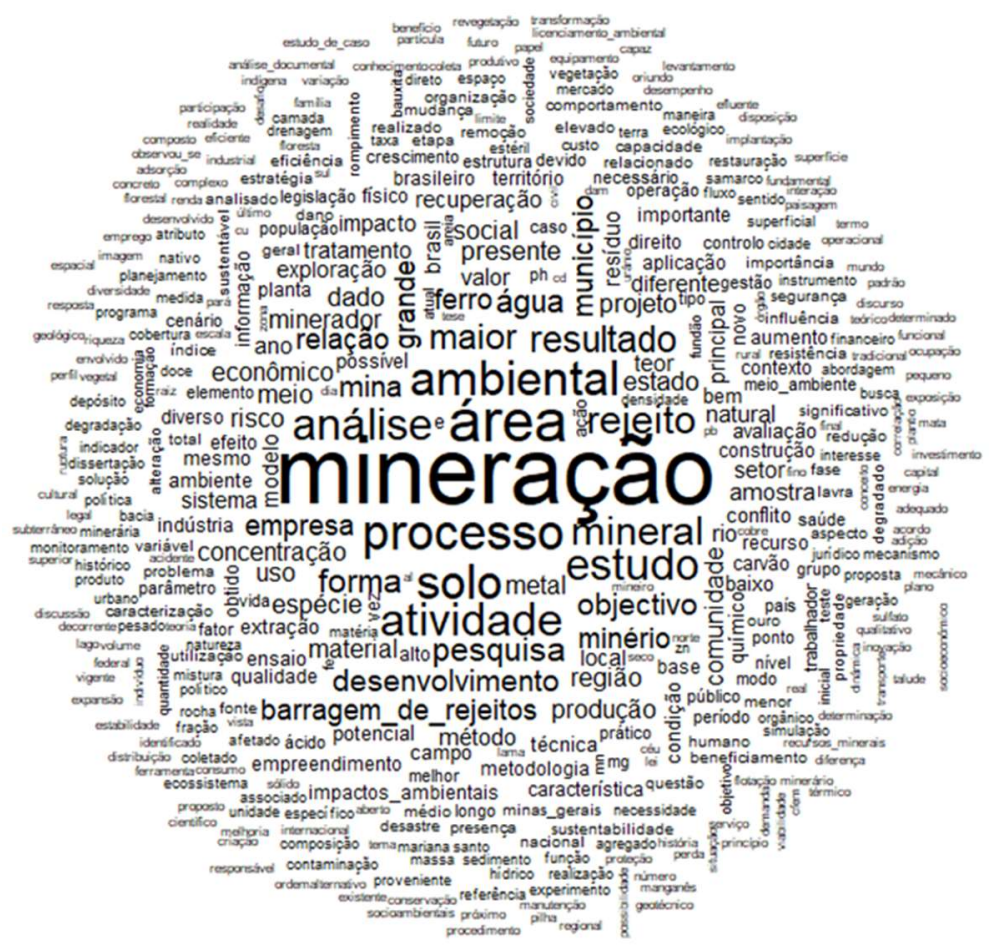

Figura 2: Nuvem de palavras utilizadas nos resumos e como palavras-chaves.

A segunda palavra mais utilizada foi a palavra 'área'. Esta ocorrência destaca a mineração como uma atividade localizada territorialmente. Os estudos se dedicam com frequência a analisar impactos da mineração na área de influência do empreendimento. Este aspecto é reforçado considerando, ainda, a referência a palavras como: 'município'; 'municipal'; 'cidade'; 'comunidade'. A recorrência das palavras 'federal' e 'lei' sugerem a presença de uma discussão temática sobre a questão do marco legal da mineração. 
A palavra 'processo' chama atenção para os aspectos técnicos que são objeto de alguns estudos, havendo pouca relação com a ideia de processos sociais. Enquanto o termo 'ambiental' destaca a relação entre a atividade mineradora e o Meio Ambiente. Destaca-se principalmente estudos sobre licenciamento ambiental, impacto ambiental e sustentabilidade. Os estudos também versam sobre temas relacionados aos impactos da mineração sob diferentes aspectos: econômico, social, cultural, caracterizando a atividade como altamente impactante (positiva ou negativamente) dentro de uma localidade. Há especial atenção ao tema do desenvolvimento nas regiões de mineração.

Os riscos da mineração são frequentemente destacados. A recorrência da categoria 'conflito' sugere a manifestação de interesses divergentes em áreas de mineração, com destaque para conflitos relacionados ao trabalho, à terra e à água. Destaca-se também a ação do poder público, das empresas e dos movimentos sociais em áreas de mineração enquanto um tema recorrente. Neste caso, além das palavras referidas à tais atores, também se destaca o uso da palavra 'governança', apontando para o tema da cooperação e coordenação entre os atores locais em áreas mineradoras.

A alta frequência do termo 'barragem de rejeitos', tematiza aspectos técnicos da construção de barragens, mas predomina os estudos de aspectos relacionados ao caso de Mariana. Os estudos relacionados sobre o tema ampliam-se analisando os efeitos do rompimento da barragem do fundão por toda a bacia do Rio Doce, tanto do ponto de vista biológico, quanto social. A referência à empresa Samarco é recorrente nos estudos.

Algumas regiões mineradoras se destacam no estudo. Os principais estados brasileiros de referência nos estudos são Minas Gerais e Pará, mas há estudos na Amazônia, Rio Grande do Sul, Santa Catarina. A região de Carajás recebe especial atenção.

\section{A posição relativa das áreas e as instituições em relação aos temas e conceitos na produção do conhecimento sobre a atividade mineradora}

Os resultados da análise de Classificação Hierárquica Decrescente (CHD) realizada no software Iramuteq permitiu identificar 6 classes temáticas entre os 688 estudos analisados. Com base nestas classes, analisamos a posição relativa das áreas de conhecimento e das instituições responsáveis pelos estudos dentro do campo. Neste estudo foram classificados $94,88 \%$ dos segmentos de textos. Deve-se destacar que para garantir a validade da análise é recomendável alcançar o mínimo de $70 \%$ de segmentos de textos classificados.

A figura 3 mostra a hierarquia entre as classes encontradas. A classe 1 é composta por $12 \%$ de segmentos de textos; a classe 2 reúne 13,5\%; a classe 3,22,5\%; a classe 4, 20,1\%, a classe 5, 15,2\%; a classe 6 contém 16,8\%. O Dendograma na figura 1 mostra uma maior aproximação entre as classes 1, 2 e 5, por um lado, e as classes 3, 4 e 6, por outro. As classes 3 e 4 reúnem as maiores quantidades de segmentos de textos.

Examinamos a posição das áreas de conhecimento e das instituições de ensino e pesquisa em relação às 6 classes temáticas identificadas acima. Nosso objetivo foi analisar em que medida as áreas e as instituições onde os estudos foram realizados se aproximam ou se distanciam entre si. Na figura 4 o tamanho 
da fonte mostra a força da associação das áreas e das instituições às 6 classes (diferenciadas por cor) conforme a estatística qui-quadrado $\left(\chi^{2}\right)^{3}$.

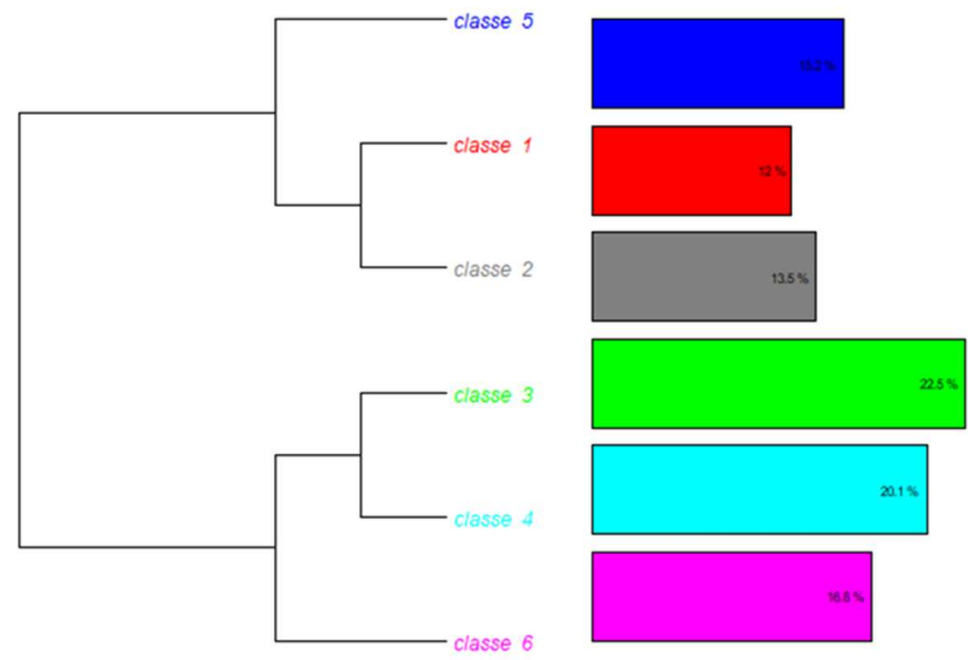

Figura 3: Dendograma da CHD.

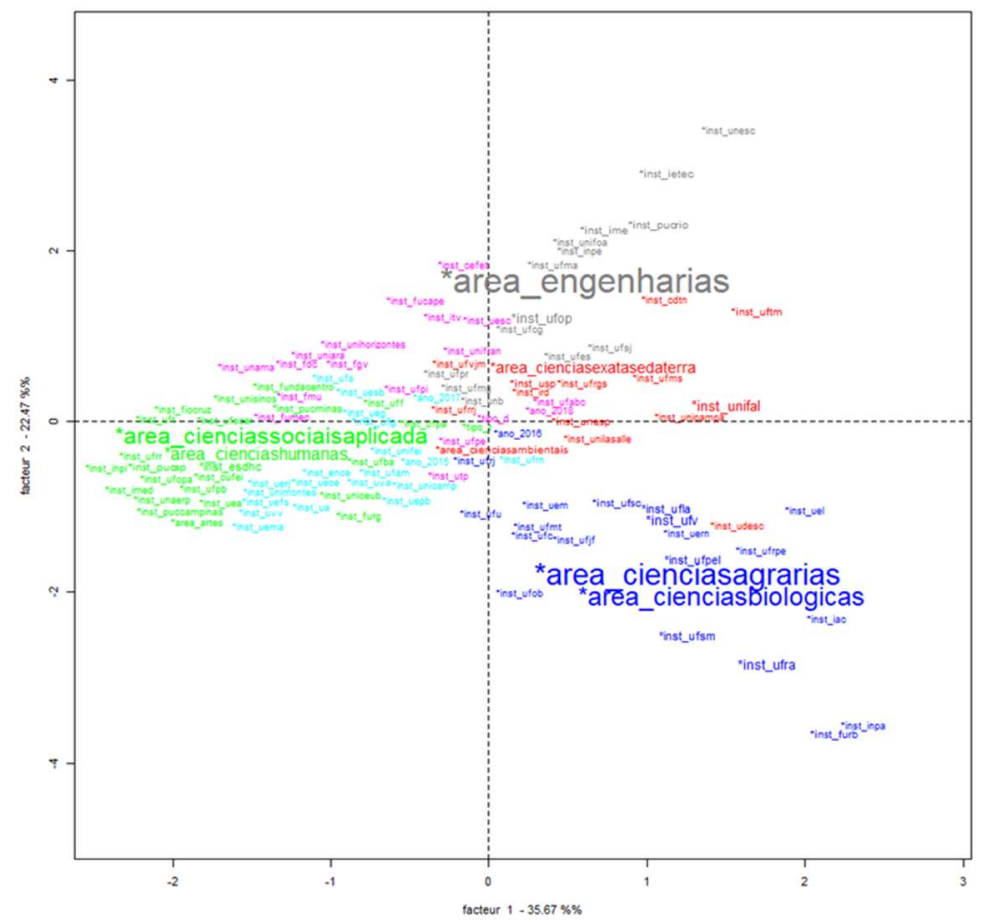

Figura 4: Localização das áreas de conhecimento e instituições das pesquisas em relação às classes da CHD-

\section{Classe 1 - Áreas de Conhecimento, Instituições e Conteúdo}

A figura 3 mostra que as áreas de Ciências Exatas da Terra $\left(\chi^{2}=304,21\right)$ e Ciências Ambientais $\left(\chi^{2}=\right.$ $59,23)$ abordam a atividade mineradora de forma semelhante. Ambas apareceram fortemente associadas à classe 1. Outras duas áreas apresentaram associação significativa à classe, todavia uma associação mais fraca se comparada às duas primeiras, são elas: áreas de Engenharias $\left(\chi^{2}=13,86\right)$ e Ciências Biológicas $\left(\chi^{2}=5,14\right)$.

A análise da relação das instituições com a classe 1 revela que a instituição com maior associação

${ }^{3}$ Sobre qui-quadrado consulte Agresti et al. (2012). 
com esta classe $\left(\chi^{2}=235,43\right)$ foi a Universidade Federal de Alfenas (Unifal-MG) com dissertações dos programas de pós-graduação em Ciências Ambientais e em Ciências e Engenharia Ambiental. Os trabalhos abordam em sua maioria o tema do tratamento, considerando a remoção de metais provenientes de drenagem ácida. Outras instituições neste grupo e os respectivos programas são: Universidade de São Paulo $\left(\chi^{2}=53,96\right)$, tendo a Engenharia Mineral como programa de maior destaque. Em seguida, Universidade Federal do Triângulo Mineiro (UFTM), $\chi^{2}=52,18$, destaca-se na área de Engenharias, com trabalhos no programa de inovação tecnológica. Já a Universidade Estadual Paulista (UNESP), $\chi^{2}=50,48$, produziu dissertações e teses principalmente na área de Ciências Ambientais. Entre os programas destacam-se as pósgraduações em Ciências Ambientais e em Geociências e meio ambiente. No geral, a classe 1 é composta por trabalhos sobre aspectos químicos e processos da mineração.

\section{Classe 2 - Áreas de conhecimento, Instituições e Conteúdo}

A área de Engenharias, além de aparecer fracamente associada à classe 1, se destacou como um tipo de abordagem particularmente associada à classe $2\left(\chi^{2}=1.328,83\right)$. Nesta classe a instituição de maior peso é a Universidade Federal de Ouro Preto (UFOP), $\chi^{2}=168,72$, principalmente com trabalhos elaborados nos programas de pós-graduação em Engenharia Ambiental e Geotécnica/Engenharia Geotécnica. Todavia, os programas de Engenharia de Materiais, Engenharia Civil e Engenharia Ambiental também produziram estudos sobre mineração. $O$ Instituto Militar de Engenharia (IME) está fortemente associado a esta classe ( $\chi^{2}$ $=97,22)$ com dissertações do programa de Engenharias de Transportes que analisam a questão do uso de rejeitos na mistura asfáltica. Destaca-se também a PUC-RIO $\left(\chi^{2}=985,00\right)$ e o Instituto de Educação Tecnológica (IETEC) $\left(\chi^{2}=50,29\right)$ com estudos na área de Engenharias. O IETEC destaca-se no seu programa de engenharia e gestão de processos e sistemas, especialmente. Enquanto a PUC-RIO destaca-se com a pósgraduação em Engenharia Civil. Majoritariamente, a classe 2 é composta por trabalhos sobre aspectos físicos da atividade minerária, com especial atenção para o tema dos resíduos da mineração.

\section{Classe 3 - Áreas de conhecimento, Instituições e Conteúdo}

A áreas de Ciências Sociais Aplicadas $\left(\chi^{2}=712,16\right)$ e Ciências Humanas $\left(\chi^{2}=410,85\right)$ associam-se fortemente à classe 3. A Escola Superior Dom Helder Câmara (ESDHC) é a instituição mais fortemente associada à esta classe $\left(\chi^{2}=139,86\right)$ por ter um grande número de dissertações sobre o tema, com enfoque nos programas de direito ambiental e desenvolvimento sustentável. Os trabalhos versam de temas como: a responsabilidade civil das mineradoras por inobservância de medidas cautelares, a necessidade de um direito penal secundário considerando a ameaça da atividade minerária um risco para o desenvolvimento de bens jurídicos coletivos frente a sociedade de risco. Outros trabalhos apresentados defendem a análise jurídica do fechamento de mina como instrumento de proteção ambiental, assim como medidas compensatórias para o desenvolvimento sustentável. A segunda instituição com maior força de associação à classe 3 foi a PUC-SP $\left(\chi^{2}=80,87\right)$ com seu programa de pós-graduação em direito e um trabalho no programa de pós-graduação em economia. As teses defendidas nesta instituição, em sua maioria, destacam os seguintes temas: impactos 
e danos ambientais; direito, mineração e desenvolvimento; licenciamento ambiental e desenvolvimento ambiental. Em sua maioria, a classe 3 é composta por trabalhos sobre aspectos sociopolíticos da mineração.

\section{Classe 4 - Áreas de conhecimento, Instituições e Conteúdo}

A área de conhecimento de maior força de associação à classe 4 foi as Ciências Humanas $\left(\chi^{2}=170,32\right)$. As áreas de Ciências Ambientais $\left(\chi^{2}=38,52\right)$ e Ciências Sociais Aplicadas $\left(\chi^{2}=21,19\right)$ também aparecem na classe 4. Já a instituição que apresentou maior força de associação com esta classe foi a Universidade Federal de Goiás (UFG) com $\chi^{2}=89,08$. Nesta instituição, ganha-se destaque os programas de pós-graduação em de Geografia, História, Direito Agrário e Gestão Organizacional. As teses defendidas abordam as transformações e conflitos socioambientais, os aspectos econômicos e sociais, bem como os conflitos e condições de trabalho decorrentes da mineração. Há trabalhos que discutem a reestruturação produtiva, a educação, o trabalho e os trabalhadores vinculados a atividade minerária.

A Universidade Estadual de Goiás (UEG) também aparece nesta classe $\left(\chi^{2}=36,61\right)$ com dissertações que apresentam as mudanças socioespaciais, com enfoque no cerrado. Os programas em destaque são voltados para os recursos naturais do Cerrado e territórios e expressões culturais no Cerrado. A Escola Nacional de Ciências Estatísticas (UNCE) também aparece nesta classe $\left(\chi^{2}=27,85\right)$ com o programa de pósgraduação em População, Território e Estatísticas Públicas. No geral, a classe 4 é composta principalmente por trabalhos que abordam os aspectos econômicos e sociopolíticos da mineração.

\section{Classe 5 - Áreas de conhecimento, Instituições e Conteúdo}

É notória a relevância da área de Ciências Agrárias para a classe $5\left(\chi^{2}=1093,00\right)$, bem como da área de Ciências Biológicas $\left(\chi^{2}=842,82\right)$. A instituição de maior peso foi a Universidade Federal Rural da Amazônia $\left(\chi^{2}=197,73\right)$ com as dissertações dos programas de Ciências Florestais e Agronomia, cujo os temas giram em torno dos métodos e efeitos na restauração do solo e da vegetação florestal no Pará. Destaca-se ainda a Universidade Federal de Viçosa (UFV), $\chi^{2}=170,18$. Em especial os programas de Extensão Rural, Ciência Florestal e Microbiologia Agrícola. A Universidade Federal de Lavras (UFLA), $\chi^{2}=155,70$, principalmente com os programas de Engenharia Florestal, Ciência do Solo e Engenharia de Biomateriais aparece associada à essa classe. Os trabalhos na UFLA abordam em sua maioria os atributos físicos, químicos e biológicos dos rejeitos oriundos da mineração e as possibilidades de tratamento e recuperação do solo. Além disso, há dissertações que abordam os movimentos sociais e a formulação de políticas públicas, bem como os desafios de cooperativas em Minas Gerais. Há pesquisas que abordam a recuperação, conservação e sustentabilidade da atividade minerária, tal como a eficiência e a diversidade de comunidades.

Outras instituições associadas à classe 5 são: Universidade Federal de Santa Maria (UFSM), $\chi^{2}=$ 136,86 com destaque para o programa de pós-graduação em Engenharia Florestal. Com $\chi^{2}=123,56$, a Universidade Federal de Pelotas (UFPel) produziu trabalhos que abordam a questão minerária sobre o ponto de vista do manejo e conservação do solo e da água, especialmente. Já na Universidade Federal de Santa Catarina (UFSC), $\chi^{2}=78,33$, os trabalhos foram realizados em diversas áreas, tais como Ciências Biológicas, 
Ciências Humanas, Ciências Exatas e da Terra e Engenharia. A Universidade Regional de Blumenau (UFB) acentua-se nessa classe $\left(\chi^{2}=56,09\right)$ com o programa de Engenharia Ambiental, onde desenvolveu temas como os conflitos socioambientais e possíveis negociações. Em sua maioria, a classe 5 é composta por trabalhos sobre aspectos ecológicos, químicos e físicos voltados para a recuperação de danos causados pela mineração.

\section{Classe 6 - Conteúdo: técnicas e métodos de pesquisa.}

A classe 6 apresenta uma característica particular em relação às demais. Ela é composta por conceitos que remetem aos aspectos metodológicos utilizados nas pesquisas. Observamos que os trabalhos produzidos se apoiam principalmente em análises documentais, estudos de casos, pesquisas bibliográficas e entrevistas semiestruturadas. Em geral, utilizando-se de metodologias qualitativas.

\section{O quebra-cabeça dos estudos sobre a atividade mineradora}

A figura 5 mostra o conteúdo das classes no quebra-cabeça solucionado da mineração. As cores representam às classes temáticas conforme o descrito no dendograma acima. Na figura destacam-se as principais palavras segundo o grau de associação à classe, conforme a estatística qui-quadrado. O conjunto de palavras recorrentes em cada classe representa os temas a elas associados. Vale destacar, como exemplo, que os principais conceitos ligados aos aspectos sociais e políticos da mineração compõem a classe 3 (verde). Esta classe representa a contribuição mais característica das áreas de Ciências Humanas e Ciências Socais Aplicadas sobre o assunto.

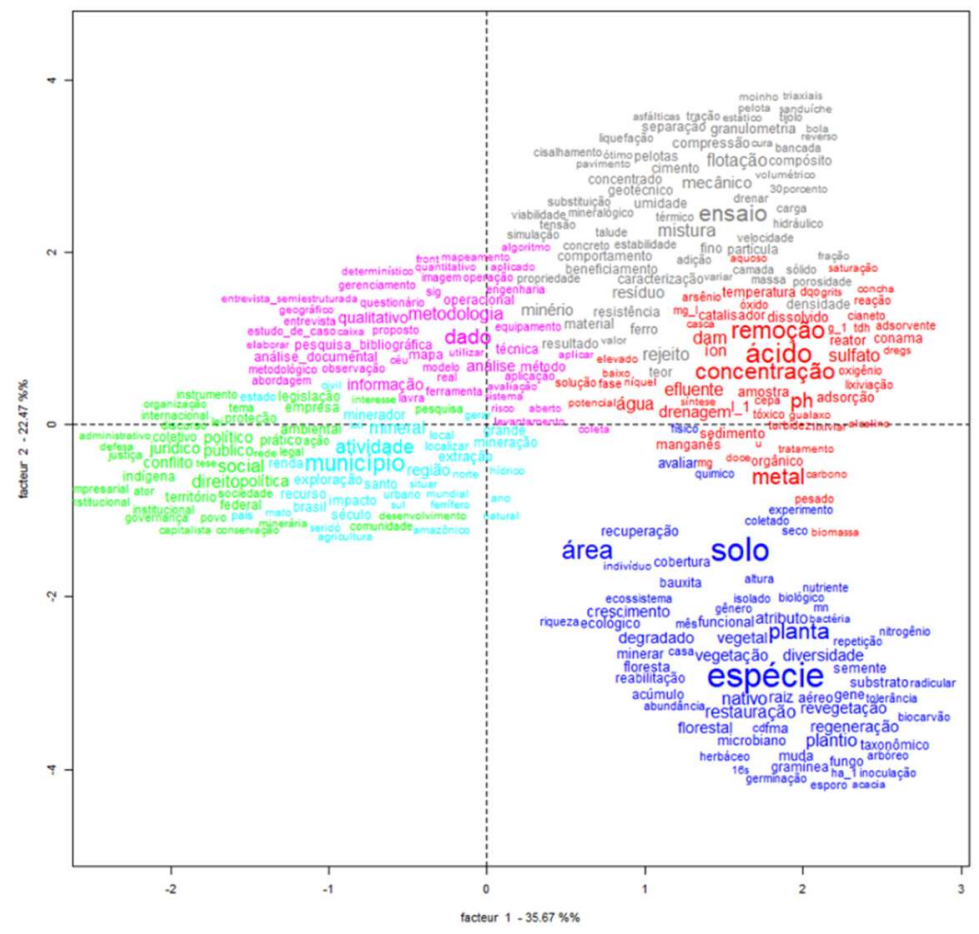

Figura 5: Localização das palavras na classe. 


\section{Discussão: campos científicos e o quebra-cabeça da mineração}

Segundo Bourdieu (1983), o campo científico constitui um "sistema de relações objetivas entre posições adquiridas (em lutas anteriores), é o lugar, o espaço de jogo de uma luta concorrencial". O campo científico é um campo de "luta pelo monopólio da competência científica", onde os atores e instituições concorrem por recursos, conhecimento e reconhecimento, respeito e poder. O campo científico encerra nas inter-relações de seus agentes uma racionalidade em termos de 'investimentos' e 'lucros' (retornos em reconhecimento). Sendo assim, tanto os pesquisadores quanto as instituições procuram maximizar seus lucros em termos de competência científica. "Assim, a tendência dos pesquisadores a se concentrar nos problemas considerados como mais importantes se explica pelo fato de que uma contribuição ou descoberta concernente a essas questões traz um lucro simbólico mais importante" (BOURDIEU, 1983).

Ora, o campo científico compreendido pela grande área das Engenharias não deixaria de angariar renome a si quanto ao conhecimento relativo ao tema da mineração. A Escola de Minas, por exemplo, foi fundada no ano de 1876, em Ouro Preto, Minas Gerais. A Escola, hoje pertencente à Universidade Federal de Ouro Preto (UFOP), foi a primeira instituição brasileira dedicada ao ensino de mineração, metalurgia e geologia. O destaque da UFOP na área de Engenharias pode ser confirmado pela forte associação desta instituição à classe 2 .

É de se esperar que o campo científico da mineração tenha sofrido uma concentração de recursos e de produção nesta área do conhecimento. No entanto, nenhum conhecimento pode ser considerado como um mundo fechado em si, independente e autônomo. O que pode ser verificado pela emergência de outras classes na análise de CHD, acima, as quais se constituem em torno de outras áreas de conhecimento que não as Engenharias. É notável que a UFOP, mesmo sendo a segunda instituição que mais produziu conhecimento no Campo Científico da Mineração, não se destacou como instituição relevante. Este achado sinaliza a necessidade de outras áreas do conhecimento na instituição dedica-se ao estudo de outras dimensões da atividade mineradora para além da dimensão técnica.

De certo, para que um campo científico seja constituído é necessário certo grau de coesão entre seus participantes, sejam eles indivíduos ou instituições. Além disso, subcampos podem ser delimitados pelos temas nos quais os cientistas se debruçam. Uma metáfora elaborada por Moody et al. (2006) compara os campos científicos a uma cadeia de montanhas em um dia de nevoeiro, onde os picos podem ser vistos, mas os vales que os conectam ficam obscuros. As interações entre os cientistas sob uma mesma temática de pesquisa fazem emergir os subcampos (os picos) e as ligações entre os subcampos (os vales) propiciam a coesão necessária para que o campo se estabeleça como uma grande área do conhecimento. Assim, as interrelações entre os pesquisadores de subcampos diversos constituem conexões ocultas que são responsáveis pela complexidade da rede. Embora este estudo não tenha analisado a rede de colaboração acadêmica via participação em banca, é possível aventar a existência de diálogo entre pesquisadores de diferentes instituições em função da presença de diferentes instituições com forte associação às classes encontradas nas análises anteriores. 
Para Maia (2016) alguns pressupostos teóricos podem ser tomados a partir dessa metáfora: (1) As ligações intergrupos permitem o fluxo de informações não redundantes, estas são responsáveis pelas ligações externas entre os subcampos, daí a importância dos laços fracos (GRANOVETTER, 1973). (2) As relações entre os pesquisadores que se debruçam sobre temas em comum formam os subcampos (ou colégios invisíveis ${ }^{4}$ ), tem-se assim o fechamento da estrutura social fazendo surgir um conjunto de sanções que podem monitorar e guiar o comportamento dos atores sociais. Com isso, surgem as normas sociais e, consequentemente, a coesão social (COLEMAN, 1988). (3) Por sua vez, as conexões entre os subcampos que se dão através das lacunas, vales, ou 'buracos estruturais', são estabelecidas por atores sociais especiais, os brokers $^{5}$, como ressaltou Burt (1992).

Por fim, tanto pela metáfora do 'quebra-cabeças' quanto pela da 'cadeia de montanhas', a compreensão de uma temática científica não pode ficar restrita apenas ao ponto de vista de uma área do conhecimento, como a das Engenharias. A diversidade do campo requer uma compreensão do macrossistema numa concepção de sistemas complexos. Portanto, neste trabalho tomou-se dessa ótica para mapear a produção científica na temática da mineração identificando como os subcampos se complementam.

\section{CONCLUSÕES}

Os dados apresentados mostram que o assunto mineração reúne temas de interesse de diferentes áreas do conhecimento. Os resultados demonstraram, ainda, uma tendência de crescimento de trabalhos sobre o assunto entre de 2015 a 2018, seguido de uma queda em 2019. Observou-se que 2018 foi o ano em que mais se produziu trabalhos de pós-graduação sobre o tema no período. Estes achados colocam a seguinte questão: Por que houve um aumento considerável na conclusão de teses e dissertações sobre mineração no ano de 2018 e uma queda subsequente em 2019? Nossa hipótese, a ser investigada, é que o evento do rompimento da 'Barragem do Fundão' em Mariana despertou o interesse de novos pesquisadores para temas relacionados à mineração.

Em relação à contribuição relativa das áreas de conhecimento, a área de Engenharias ocupa lugar central. Todavia, chamou a atenção o fato das áreas de Ciências Sociais Aplicadas e Ciências Humanas terem produzido mais estudos que áreas mais naturalmente ligadas à questão da mineração, tais como: Ciências Ambientais e Ciências Exatas da Terra. Sobre este ponto destacamos o seguinte enigma: Por que isso foi possível?

A análise sobre as principais instituições que pesquisam o assunto, mostrou que a maioria são Universidades Públicas, principalmente federais. Destacaram-se a UFMG, a UFOP e a USP como as instituições onde se mais produziu conhecimento sobre os temas relacionados à atividade mineradora.

\footnotetext{
${ }^{4}$ Colégios invisíveis definem grupos de pesquisadores que possuem algum objeto de pesquisa em comum e mantém laços de comunicação, mesmo que não pertencentes a uma mesma organização.

${ }^{5}$ Brokers são os atores, os nós das redes, que se situam nas extremidades das pontes entre subgrupos (clusters). Eles desempenham uma função de "corretagem", brokerage, pois desfrutam de benefícios proporcionados por estarem conectados através de buracos estruturais, eles podem acessar diversas informações novas, vindas de fora do grupo a que pertencem.
} 
Sendo que a produção da UFOP se encontra especialmente associada à área de Engenharias.

Os nossos resultados mostram que os estudos se estruturam em 5 classes temáticas organizadas em torno de composições de Área e uma classe sobre o tema: metodologia. A área de Engenharias é a única a ter uma classe associada exclusivamente a ela (Classe 2). As demais classes estão mais fortemente associadas à Ciências Exatas e da Terra e Ciências Ambientais (Classe 1); Ciências Sociais Aplicadas e Ciências Humanas (Classe 3); Ciências Humanas, Ciência Ambientais e Ciências Sociais Aplicadas (Classe 4); e Ciências Agrárias e Ciências Biológicas (Classe 5).

Considerando o campo dos estudos organizacionais, especialmente a sociologia organizacional, sugerimos um conjunto de questões para a composição de uma agenda de pesquisa relacionada à atividade mineradora a ser desenvolvida. Sugere-se investigar como a mineração molda a organização social em sua área de abrangência, ao mesmo tempo que sobre influência dos processos sociais locais. Assim interessa saber: Quais os efeitos do empreendimento minerário sobre (1) a ecologia da comunidade organizacional local; (2) sobre a organização social de base voluntária; (3) sobre as inovações sociais e suas tecnologias; (4) sobre as ações do poder público local; e (5) como processos sociais locais afetam os empreendimentos mineradores?

\section{REFERÊNCIAS}

AGRESTI, A.; FINLAY, B.. Métodos estatísticos para as ciências sociais. Porto Alegre: Penso, 2012.

BOURDIEU, P.. Questões de sociologia. Rio de Janeiro: Marco Zero, 1983.

BURT, R. S.. Structural Holes: The Social Structure of Competition. Cambridge: Harvard University Press, 1992.

COLEMAN, J. S.. Social Capital in the Creation of Human Capital. Supplement: Organizations and Institutions: Sociological and Economic Approaches to the Analysis of Social Structure. The American Journal of Sociology, v.94, p.S95-S120, 1988.

DUVAL, J.. Analisar um espaço social. In: PAUGAM, S.. A pesquisa sociológica. Petrópolis: Vozes, 2015.

GRANOVETTER, M.. The Strengh of Weak Ties. American Journal of Sociology, v.78, n.6, p.1360-1380, 1973.
MAIA, V. I.. O campo da Sociologia no Brasil: a estrutura relacional e os condicionantes do isomorfismo institucional. Tese (Doutorado em Sociologia) - Faculdade de Filosofia e Ciências Humanas da Universidade Federal de Minas Gerais, Belo Horizonte, 2016.

MOODY, J.; LIGHT, R.. A View from Above: The Evolving Sociological Landscape. The American Sociologist, v.37, n.2, p.67-86, 2006.

REINERT, M.. Les "Mondes lexicaux" et leur "logique" à travers de l'analyse statistique d'un corpus de récits de cauchemars. Langage et Société, v.66, n.1, p.5-39, 1993.

ZIPF, G. K.. Human behaviour and the principle of least effort. Cambridge: Addison-Wesley, 1949. DOI: http://doi.org/10.1002/1097-4679(195007)6:3<306::AIDJCLP2270060331>3.0.CO;2-7

A CBPC - Companhia Brasileira de Produção Científica (CNPJ: 11.221.422/0001-03) detém os direitos materiais desta publicação. Os direitos referem-se à publicação do trabalho em qualquer parte do mundo, incluindo os direitos às renovações, expansões e disseminações da contribuição, bem como outros direitos subsidiários. Todos os trabalhos publicados eletronicamente poderão posteriormente ser publicados em coletâneas impressas sob coordenação da Sustenere Publishing, da Companhia Brasileira de Produção Científica e seus parceiros autorizados. Os (as) autores (as) preservam os direitos autorais, mas não têm permissão para a publicação da contribuição em outro meio, impresso ou digital, em português ou em tradução. 